\title{
Endoscopic treatment of variceal upper gastrointestinal bleeding: European Society of Gastrointestinal Endoscopy (ESGE) Cascade Guideline
}

\section{Authors}

John Gásdal Karstensen ${ }^{1,2}$, Alanna Ebigbo ${ }^{3}$, Purnima Bhat ${ }^{4}$, Mario Dinis-Ribeiro ${ }^{5,6}$, Ian Gralnek ${ }^{7}$, Claire Guy ${ }^{8}$, Olivier Le Moine $^{9}$, Peter Vilmann ${ }^{10}$, Giulio Antonelli ${ }^{11}$, Uche ljoma ${ }^{12}$, Gideon Anigbo ${ }^{13}$, Mary Afiheni ${ }^{14}$, Babatunde Duduyemi ${ }^{15}$, Hailemichael Desalegn ${ }^{16}$, Roberto De Franchis ${ }^{17}$, Thierry Ponchon ${ }^{18}$, Cesare Hassan ${ }^{19}$, Lars Aabakken ${ }^{20}$

\section{Institutions}

1 Hvidovre Hospital - Gastro Unit, Hvidovre, Denmark

2 University of Copenhagen - Department of Clinical Medicine, Copenhagen, Denmark

3 Central Clinic of Augsburg - Gastroenterology, Augsburg, Germany

4 ANU Medical School/Canberra Hospital Gastroenterology, Garran, Australia

5 Instituto Português de Oncologia - Gastrenterologia, Porto, Portugal

6 Porto Faculty of Medicine - Biostatistics and Medical Informatics, Porto, Portugal

7 Emek Medical Center - Gastroenterology and Hepatology, Afula, Northern Israel

8 European Society of Gastrointestinal Endoscopy Munich, Germany

9 Hopital Erasme, Université Libre de Bruxelles Department of Gastroenterology Brussels, Belgium

10 Copenhagen University Hospital Herlev - Gastro Unit, Herlev, Denmark

11 Azienda Ospedaliera Sant'Andrea - Sapienza University of Rome, Digestive and Liver Disease Unit, Rome, Italy

12 University of Nigeria Teaching Hospital - Department of Gastroenterology, Enugu, Nigeria

13 Enugu State University Teaching Hospital Department of Medicine, Enugu, Nigeria

14 Kwame Nkrumah University of Science and Technology - Department of Medicine, Kumasi, Ghana
15 Kwame Nkrumah University of Science and Technology - Department of Pathology, Kusami, Ghana

16 St. Paul's Hospital Millenium Medical College Department of Internal Medicine, Addis Ababa, Addis Ababa, Ethiopia

17 University of Milan, IRCCS Maggiore Policlinico Hospital - Department of Internal Medicine Gastroenterology and Digestive Endoscopy Service, Milan, Italy

18 Edouard Herriot Hospital - Hepatogastroenterology, Lyon, France

19 ONRM Hospital - Gastro, Rome, Italy

20 Dept of transplantation medicine, Oslo University Hospital - Rikshospitalet, Oslo, Norway and Faculty of Medicine, University of Oslo, Norway

submitted 19.5.2020

accepted after revision $\quad 21.5 .2020$

Bibliography

DOI https://doi.org/10.1055/a-1187-1154 |

Endoscopy International Open 2020; 08: E990-E997

(c) Georg Thieme Verlag KG Stuttgart · New York elSSN 2196-9736

Corresponding author

Cesare Hassan, ONRM Hospital - Gastro, Via Morosini 30,

Rome 00153, Italy

Fax: +390658446533

cesareh@hotmail.com 


\section{Introduction}

Patients with variceal gastrointestinal bleeding are encountered daily in endoscopic departments around the world. Risk factors include infectious diseases such as hepatitis B and C virus and schistosomiasis, as well as alcohol consumption and metabolic syndrome with development of nonalcoholic fatty liver disease [1]. Globally, prevalence and incidence of chronic liver disease and cirrhosis varies markedly between countries [2]. High-quality epidemiological data from the majority of African countries are lacking; nevertheless, development of cirrhosis and related consequences are a major burden for public health systems in the continent [2-4]. In Africa, mortality from cirrhosis is estimated at 12.9 to 24.2 per 100,000 person-years range and prevalence of hepatitis $B$ virus is among the highest in the world at 6,100 per 100,000 inhabitants $[5,6]$.

The latest update of the Baveno guideline describes in detail how to prevent and manage variceal bleeding, as well as how to avoid recurrent bleeding [7]. The majority of recommendations in the guideline are based on high levels of evidence and many years of practice. However, some of the recommendations are resource-sensitive and may be unavailable in low-resource settings due to factors such as extensive costs, lack of sufficient health professional training and logistical limitations.

The European Society of Gastrointestinal Endoscopy (ESGE) has implemented a cascade methodology in a joint effort with the World Endoscopy Organization (WEO), aiming to adapt existing guidelines to make them applicable to resource-limited regions (including some African countries) [8]. Previously, two cascade guidelines have been published focusing on endoscopic management of non-variceal upper gastrointestinal bleeding and upper gastrointestinal obstruction, respectively [8-10]. This ESGE cascade guideline aims to standardize endoscopic management of patients with variceal gastrointestinal bleeding.

\section{Methods}

The methodology of the cascade guidelines has been described in the ESGE position paper [8]. Briefly, endoscopy-related statements from the Baveno $\mathrm{VI}$ guideline were extracted after agreement with the European Association for the Study of Liver [7]. Following that step, members of the International Affairs Working Group (IAWG) independently categorized the statements as resource-sensitive or not. Those with an agreement of $50 \%$ or more for being resource-sensitive were selected for the revision process and subsequently, adaptions were suggested for the four previously defined resource levels ( Table 1 ) [8]. The selection of statements, as well as the adaption process, was guided by an external panel of five colleagues from Nigeria, Ghana, and Ethiopia, as well as collaborating WEO outreach committee members.

The modified statements were then subject to a Delphi process with local doctors invited by a dedicated mailing list representative of gastroenterology specialists in different areas of Africa, where a rate of agreement of $75 \%$ or higher of all adaptions for all resource levels led to acceptance of the cascade statement [11]. If a $75 \%$ agreement was not reached, the statement was subject to another round of modification before a final Delphi process was carried out.

\section{Results \\ Cascade statements}

Statement selection: 50 of 199 statements from the original BAVENO VI guideline were selected as resource-sensitive. Three adapted cascade statements - one for each level, excluding the IV as corresponding to the original guideline - were created for each of the original recommendations, making a total of 150 adapted cascade guideline statements.

Delphi process: Overall, 205 experts showed an interest in participating in the Delphi process. Finally, 38 experts from 16 countries participated in the Delphi process, expressing their degree of agreement with one or more recommendations. Details of the participants are provided in > Table 2 . A $\geq 75 \%$ agreement was achieved for 49 of 50 proposed adaptations.

\footnotetext{
- Table 1 Level of treatment care.

I: Basic Core resources or fundamental services absolutely necessary for an endoscopy care system to function. By definition, a health care system lacking any basic level resource would be unable to provide endoscopic service to its patient population. It includes diagnostic procedures (gastroscopy and colonoscopy) as well and fundamental monitoring abilities (blood pressure, basic blood biochemistry).

II: Limited Second-tier resources or services that produce major improvements in outcome, such as increased survival, but that are attainable with limited financial means and modest infrastructure. It includes minor endoscopic procedures to improve major clinical outcomes (i. e. sclerotherapy/adrenaline injection, band ligation, plasma expanders, basic surgical interventions).

III: Enhanced Third-tier resources or services that are optional but important. Enhanced-level resources may produce minor improvements in outcome but increase the number and quality of therapeutic options. Most procedures that improves clinical outcome are available (i. e. biliopancreatic endoscopy, electrosurgical unit, polypectomy/mucosectomy, anaesthesia back-up).

IV: Maximal High-level resources or services that may be used in some high-resource countries or be recommended in guidelines that assume unlimited resources. To be useful, maximal-level resources typically depend on the existence and functionality of all lower-level resources.
} 
- Table 2 Characteristics of the participants in the Delphi Process.

Number of participants

$\mathrm{N}=\mathbf{3 8}$

\begin{tabular}{|l|c|}
\hline \multicolumn{2}{|l|}{ Geographical area } \\
\hline North Africa (\%) & $20(52.6 \%)$ \\
\hline Central Africa (\%) & $3(7.9 \%)$ \\
\hline East Africa (\%) & $6(15.8 \%)$ \\
\hline West Africa (\%) & $8(21 \%)$ \\
\hline South Africa (\%) & $1(2.6 \%)$ \\
\hline
\end{tabular}

Socioeconomic status of institution/hospital

\begin{tabular}{|c|c|}
\hline High (\%) & $1(2.6 \%)$ \\
\hline Mid (\%) & $14(36,8 \%)$ \\
\hline Low (\%) & $23(60.5 \%)$ \\
\hline
\end{tabular}

One cascade adaptation recommendation on the role of covered self-expanding metal stents (C-SEMS) for refractory bleeding failed to achieve the $\geq 75 \%$ agreement level. The comments provided by the participants pointed towards the unavailability of C-SEMS and balloon tamponade for treatment of refractory variceal bleeding. For that reason, the statements were revised to include best supportive care and non-selective beta blocker (NSBB) treatment in Levels I and II.

Cascade adaptation: Each original recommendation with the accepted adaptations is reported in $>$ Table 3 . It was assumed that basic endoscopy is available at all levels of care. However, added to the availability of endoscopy, some specific resources influenced the adaptation of the original guidelines and can be categorized as follows:

1. Pharmacological treatment

2. Therapeutic endoscopy

3. Interventional radiology and surgery

4. Pharmacological treatment

At the basic level, best supportive care and NSBB treatment were recommended as adaptations for primary as well as secondary prophylaxis of variceal hemorrhage. Octreotide was the recommended adaptation when urgent endoscopic treatment of active bleeding episodes was not available.

1. Endoscopic treatment

a) Esophageal varices

At the most basic level, band ligation of varices is the treatment of choice in our adaptation. It is available in most centers and represents the most effective endoscopic treatment for acute esophageal variceal bleeding and for secondary prophylaxis. However, round-the-clock availability of emergency endoscopic services may be limited, representing the main difference between Levels I and II. Thus, timing of endoscopy may be delayed, worsened by a lack of availability of blood transfusion at Level 1. Thus, we recommended as a possible adaptation use of octreotide and supportive care. b) Gastric varices

Injection of tissue adhesive (cyanoacrylate) does not require a high level of technical expertise. Unfortunately, it is not available at the basic and limited levels. For that reason, treatment of acute bleeding from isolated gastric varices with band ligation can be considered even though evidence for this procedure is limited [12].

c) Refractory bleeding

For endoscopic rescue treatment, balloon tamponade and SEMS are not available at the basic level. They can be recommended only in some centers at the limited level, but in all centers at the enhanced level.

\section{Radiologic and surgical treatment}

Transjugular intrahepatic portosystemic shunt (TIPS), balloonoccluded retrograde transvenous obliteration (BRTO), and surgical options such as the mesenteric-left portal vein bypass (Meso-Rex operation) are not available except at the enhanced resource level. For prevention of recurrent variceal hemorrhage, maximal endoscopic and pharmacological treatment options should be exhausted.

Endoscopic treatment of gastroesophageal varices represents by far the most life-saving endoscopic intervention in most of developing African countries given the high prevalence of viral and parasitic liver infections. For that reason, primary endoscopic treatment - i. e. band ligation - has become available also at Level II in most centers, providing a favorable prognosis for patients with active bleeding. However, technical feasibility may be hampered by irregular provision of endoscopic resources such as training, scope maintenance, and availability of ligators.

Despite endoscopy's prominent role in this condition, resources for it are not easily accessible for most patients with gastroesophageal varices due to limited capacity, long distances or costs. In this context, use of NSBB is consistently recommended through Level I and II as a less effective but more widely available resource.

Treatment of gastric varices remains challenging. The main priority is adequate and cost-effective supply of tissue adhesive to developing countries as the technical feasibility for its injection is available. Alternatively, band ligation or NSBB may represent surrogate treatments.

\section{Conclusion}

In conclusion, endoscopic treatment of variceal bleeding represents the most life-saving endoscopic intervention in most developing countries. In a resource-limited situation, adaptation of general guidelines may help optimize endoscopic care in this patient group. 
- Table 3 Adaptation of recommendations according to level of treatment care.

Original statements

Suggested modifications

Surveillance of esophageal varices

1 In compensated patients with no varices at screening endoscopy and with ongoing liver injury (e. g. active drinking in alcoholics, lack of SVR in HCV), surveillance endoscopy should be repeated at 2-year intervals.

2 In compensated patients with small varices and with ongoing liver injury (e. g. active drinking in alcoholics, lack of SVR in HCV), surveillance endoscopy should be repeated at 1 -year intervals.

3 In compensated patients with no varices at screening endoscopy in whom the aetiological factor has been removed (e. g. achievement of SVR in HCV; long-lasting abstinence in alcoholics) and who have no co-factors (e. g. obesity), surveillance endoscopy should be repeated at three year intervals.

4 In compensated patients with small varices at screening endoscopy in whom the etiological factor has been removed (e. g. achievement of SVR in HCV; long-lasting abstinence in alcoholics) and who have no co-factors (e. g. obesity), surveillance endoscopy should be repeated at 2-year intervals).

Patients with no varices or small varices

5 Patients with small varices with red whale marks or Child-Pugh C class have an increased risk of bleeding and should be treated with non-selective beta blockers (NSBB).

6 Patients with small varices without signs of increased risk may be treated with NSBB to prevent bleeding. Further studies are required to confirm their benefit.

Level I/II/III: No adjustment

Level I/II/III: No adjustment

Level I/II/III: No adjustment

Patients with medium-large varices

7 Either NSBB or endoscopic band ligation is recommended for the prevention of the first variceal bleeding of medium or large varices.

8 The choice of treatment should be based on local resources and expertise, patient preference and characteristics, contraindications and adverse events.

Patients with gastric varices

9 Although a single study suggested that cyanoacrylate injection is more effective than beta blockers in preventing first bleeding in patients with large gastroesophageal varices type 2 or isolated gastric varices type 1, further studies are needed to evaluate the risk/benefit ratio of using cyanoacrylate in this setting before a recommendation can be made).

Management of the acute bleeding episode

Blood volume restitution

10 The goal of resuscitation is to preserve tissue perfusion. Volume restitution should be initiated to restore and maintain hemodynamic stability.

11 Packed red blood cells transfusion should be done conservatively at a target haemoglobin level between 7 and $8 \mathrm{~g} / \mathrm{dl}$, although transfusion policy in individual patients should also consider other factors such as cardiovascular disorders, age, hemodynamic status and ongoing bleeding).

12 Recommendations regarding management of coagulopathy and thrombocytopenia cannot be made on the basis of currently available data.

$13 \mathrm{PT} / \mathrm{INR}$ is not a reliable indicator of the coagulation status in patients with cirrhosis. Antibiotic prophylaxis

14 Antibiotic prophylaxis is an integral part of therapy for patients with cirrhosis presenting with upper gastrointestinal bleeding and should be instituted from admission.

Level I: NSBB

Level II: NSBB and sclerotherapy e. g. submucosal ethanol injection

Level III: No adjustment
Level I: NSBB and endoscopic surveillance every

6 months

Level II: No adjustment

Level III: No adjustment

Level I/II/III: No adjustment 
Table 3 (Continuation)

\section{Original statements}

15 The risk of bacterial infection and mortality are very low in patients with Child-Pugh A cirrhosis, but more prospective studies are needed to assess whether antibiotic prophylaxis can be avoided in this subgroup of patients.

16 Individual patient risk characteristics and local antimicrobial susceptibility patterns must be considered when determining appropriate first line acute variceal hemorrhage antimicrobial prophylaxis at each center.

17 Intravenous ceftriaxone $1 \mathrm{~g} / 24 \mathrm{~h}$ should be considered in patients with advanced cirrhosis, in hospital settings with high prevalence of quinolone-resistant bacterial infections and in patients on previous quinolone prophylaxis.

\section{Suggested modifications}

Level I/II/III: No adjustment

Level I/II/III: No adjustment

Level I: Intravenous antibiotics after local preferences and availability

Level II: No adjustment

Level III: No adjustment

Prevention of hepatic encephalopathy

18 Recent studies suggest that either lactulose or rifaximin may prevent hepatic encephalopathy in patients with cirrhosis and upper gastrointestinal bleeding. However, further studies are needed to evaluate the risk/benefit ratio and to identify high risk patients before a formal recommendation can be made.

19 Although, there are no specific studies in acute variceal bleeding, it is recommended to adopt the recent EASL/AASLD HE guidelines which state that episodic HE should be treated with lactulose $(25 \mathrm{ml} \mathrm{q} 12 \mathrm{~h}$ until $2-3$ soft bowel movements are produced, followed by dose titration to maintain 2-3 soft bowel movements per day).

20 Child-Pugh class C, the updated MELD score, and failure to achieve primary haemostasis are the variables most consistently found to predict six week mortality.

Pharmacological treatment

21 In suspected variceal bleeding, vasoactive drugs should be started as soon as possible, before endoscopy.

22 Vasoactive drugs (terlipressin, somatostatin, octreotide) should be used in combination with endoscopic therapy and continued for up to five days.

23 Hyponatremia has been described in patients under terlipressin, especially in patients with preserved liver function. Therefore, sodium levels must be monitored. Endoscopy

24 Following hemodynamic resuscitation, patients with upper gastrointestinal bleeding and features suggesting cirrhosis should undergo esophagogastroduodenoscopy within $12 \mathrm{~h}$ of presentation.

25 In the absence of contraindications (QT prolongation), pre-endoscopy infusion of erythromycin (250 mg IV 30-120 min before endoscopy) should be considered.

26 The availability both of an on-call gastrointestinal endoscopist proficient in endoscopic haemostasis and on-call support staff with technical expertise in the usage of endoscopic devices enables performance of endoscopy on a $24 / 7$ basis and is recommended.

27 Patients with acute variceal hemorrhage should be considered for ICU or other well monitored units.
Level I: Lactulose and antibiotics according to local preferences and availability

Level II: Lactulose and nonabsorbable antibiotics Level III: No adjustment

Level I: Lactulose and best supportive care

Level II: No adjustment

Level III: No adjustment

Level I/II/III: No adjustment

Level I: Octreotide

Level II: Octreotide

Level III: No adjustment

Level I: Octreotide

Level II: Octreotide and endoscopic therapy is recommended Level III: No adjustment

Level I/II/III: No adjustment

Level I. Technical expertise may not be available on a $24 / 7$ basis

Level II. Endoscopy within 24 hours; trained emergency team with necessary technical expertise available

Level III. No adjustment

Level I: Endoscopy even when pre-endoscopic erythromycin infusion is not available.

Level II: No adjustment

Level III: No adjustment

Level I. Technical expertise may not be available on a round-the clock basis

Level II. Endoscopy within 24 hours; trained emergency team with necessary technical expertise available

Level III. No adjustment

Level I: Best supportive care

Level II: Best supportive care with best available monitoring of vital parameters

Level III: No adjustment 
- Table 3 (Continuation)

\section{Original statements}

28 In patients with altered consciousness, endoscopy should be performed with protection of the airway.

29 Ligation is the recommended form of endoscopic therapy for acute oesophageal variceal bleeding.

30 Endoscopic therapy with tissue adhesive (e. g. N-butyl-cyanoacrylate) is recommended for acute bleeding from isolated gastric varices (IGV) and those gastroesophageal varices type 2 (GOV2) that extend beyond the cardia.

31 To prevent rebleeding from gastric varices, consideration should be given to additional glue injection (after 2 to 4 weeks), beta-blocker treatment or both combined or TIPS. More data in this area are needed.

32 EVL or tissue adhesive can be used in bleeding from gastroesophageal varices type 1 (GOV1).

Early TIPS placement

33 An early TIPS with PTFE-covered stents within $72 \mathrm{~h}$ (ideally $<24 \mathrm{~h}$ ) must be considered in patients bleeding from EV, GOV1 and GOV2 at high risk of treatment failure (e. g. Child-Pugh class $C<14$ points or Child-Pugh class B with active bleeding) after initial pharmacological and endoscopic therapy. Criteria for high-risk patients should be refined.

Balloon tamponade

34 Balloon tamponade, given the high incidence of its severe adverse events, should only be used in refractory oesophageal bleeding, as a temporary "bridge" (for a maximum of $24 \mathrm{~h}$ ) with intensive care monitoring and considering intubation, until definitive treatment can be instituted.

Use of self-expandable metal stents

35 Data suggest that self-expanding covered esophageal metal stents may be as efficacious and a safer option than balloon tamponade in refractory oesophageal variceal bleeding.

\section{Management of treatment failures}

36 Persistent bleeding despite combined pharmacological and endoscopic therapy is best managed by PTFE-covered TIPS.

37 Rebleeding during the first 5 days may be managed by a second attempt at endoscopic therapy. If rebleeding is severe, PTFE-covered TIPS is likely the best option.

Preventing recurrent variceal haemorrhage and other decompensating events

Prevention of recurrent variceal haemorrhage

38 First line therapy for all patients is the combination of NSBB (propranolol or nadolol) + EVL.

\section{Suggested modifications}

Level I: Patients with ongoing active hematemesis should be placed in a stable side position immediately; continuous active suction of blood and gastric contents

Level II: Stable side position; continuous sedation; continuous active suction of blood and gastric contents; emergency endoscopy Level III: No adjustment

Level I: Best supportive and octreotide Level II: No adjustment Level III: No adjustment

Level I: Best supportive care and NSBB Level II: Endoscopic band ligation can be considered as a salvage treatment in case of acute bleeding from small gastric varices when tissue adhesive is not available Level III: No adjustment

Level I: Best supportive care and NSBB Level II: NSBB and endoscopic band ligation when tissue adhesive or TIPS are not available Level III: No adjustment

Level I: Best supportive care and NSBB Level II: No adjustment Level III: No adjustment

Level I: Best supportive care and NSBB Level II: Maximal endoscopic and pharmacological therapy including NSBB when TIPS is not available Level III: No adjustment

Level I: Best supportive care and NSBB Level II: No adjustment Level III: No adjustment

Level I: Best supportive care and NSBB Level II: No adjustment Level III: No adjustment

Level I: Best supportive care and NSBB Level II: Maximal endoscopic and pharmacological therapy including NSBB when TIPS is not available Level III: No adjustment

Level I: Best supportive care and NSBB Level II: Maximal endoscopic and pharmacologica therapy including NSBB when TIPS is not available Level III: No adjustment

\begin{tabular}{|l|l|l|l|l|l}
\hline & Level III: No adjustment & \\
\hline & Preventing recurrent variceal haemorrhage and other decompensating events & \\
\hline & Prevention of recurrent variceal haemorrhage & Level I: NSBB \\
\hline 38 & $\begin{array}{l}\text { First line therapy for all patients is the combination of NSBB (propranolol or nadolol) } \\
+ \text { EVL. }\end{array}$ & $\begin{array}{l}\text { Level II: No adjustment } \\
\text { Level III: No adjustment }\end{array}$ \\
\hline
\end{tabular}


- Table 3 (Continuation)

\begin{tabular}{|c|c|c|}
\hline & Original statements & Suggested modifications \\
\hline 39 & $\begin{array}{l}\text { EVL should not be used as monotherapy unless there is intolerance/contraindica- } \\
\text { tions to NSBB. }\end{array}$ & $\begin{array}{l}\text { Level I: No adjustment } \\
\text { Level II: No adjustment } \\
\text { Level III: No adjustment }\end{array}$ \\
\hline 40 & $\begin{array}{l}\text { NSBB should be used as monotherapy in patients with cirrhosis who are unable or } \\
\text { unwilling to be treated with EVL. }\end{array}$ & $\begin{array}{l}\text { Level I: No adjustment } \\
\text { Level II: No adjustment } \\
\text { Level III: No adjustment }\end{array}$ \\
\hline 41 & $\begin{array}{l}\text { Covered TIPS is the treatment of choice in patients that fail first-line therapy (NSBB + } \\
\text { EVL). }\end{array}$ & $\begin{array}{l}\text { Level I: Best supportive care and NSBB } \\
\text { Level II: NSBB, EVL, and SEMS } \\
\text { Level III: No adjustment }\end{array}$ \\
\hline \multirow[t]{2}{*}{42} & $\begin{array}{l}\text { Because carvedilol has not been compared to current standard of care, its use cannot } \\
\text { be recommended in the prevention of rebleeding. }\end{array}$ & Level I/II/III: No adjustment \\
\hline & Secondary prophylaxis of portal hypertensive gastropathy (PHG) & \\
\hline 43 & $\begin{array}{l}\text { PHG has to be distinguished from gastric antral vascular ectasia because treatments } \\
\text { are different. }\end{array}$ & Level I/II/III: No adjustment \\
\hline 44 & NSBB are first-line therapy in preventing recurrent bleeding from PHG. & $\begin{array}{l}\text { Level I: No adjustment } \\
\text { Level II: No adjustment } \\
\text { Level III: No adjustment }\end{array}$ \\
\hline \multirow[t]{2}{*}{45} & $\begin{array}{l}\text { TIPS might be considered in patients with transfusion-dependent PHG in whom } \\
\text { NSBB and/or endoscopic therapies fail. }\end{array}$ & $\begin{array}{l}\text { Level I: NSBB } \\
\text { Level II: NSBB when TIPS is not available } \\
\text { Level III: No adjustment }\end{array}$ \\
\hline & Treatment of portal hypertension in EHPVO & \\
\hline 46 & $\begin{array}{l}\text { All patients in whom thrombosis has not been recanalized should be screened for } \\
\text { gastroesophageal varices within } 6 \text { months of the acute episode. In the absence of } \\
\text { varices, endoscopy should be repeated at } 12 \text { months and } 2 \text { years thereafter. }\end{array}$ & $\begin{array}{l}\text { Level I: No adjustment } \\
\text { Level II: No adjustment } \\
\text { Level III: No adjustment }\end{array}$ \\
\hline 47 & $\begin{array}{l}\text { There is insufficient data on whether beta blockers or endoscopic therapy should be } \\
\text { preferred for primary prophylaxis. Thus, guidelines for cirrhosis should be applied. }\end{array}$ & Level I/II/III: No adjustment \\
\hline 48 & For the control of acute variceal bleeding, endoscopic therapy is effective. & Level I/II/III: No adjustment \\
\hline 49 & $\begin{array}{l}\text { Evidence suggests that beta blockers are as effective as endoscopic ligation therapy } \\
\text { for secondary prophylaxis. }\end{array}$ & Level I/II/III: No adjustment \\
\hline 50 & $\begin{array}{l}\text { Mesenteric-left portal vein bypass (Meso-Rex operation) should be considered in all } \\
\text { children with complications of chronic EHPVO, who should be referred to centres } \\
\text { with experience in treating this condition. }\end{array}$ & $\begin{array}{l}\text { Level I: Best supportive care and NSBB } \\
\text { Level II: Maximal endoscopic and pharmacological } \\
\text { therapy including NSBB } \\
\text { Level III: No adjustment }\end{array}$ \\
\hline & anding metal stent; PHG, portal hypertensive gastropathy; EHPVO, extrahepatic portal vein ob & $\begin{array}{l}\text { ean Association for the Study of Liver; AASLD, American } \\
\text { ed gastric varices; GOV2, gastroesophageal varices type 2; } \\
\text { ageal varices type 1; PTFE, polytetrafluoroethylene; SEMS, } \\
\text { Iction }\end{array}$ \\
\hline
\end{tabular}

\section{Competing interests}

The authors declare that they have no conflict of interest.

\section{References}

[1] James SL, Abate D, Abate KH et al. GBD 2017 Disease and Injury Incidence and Prevalence Collaborators. Global, regional, and national incidence, prevalence, and years lived with disability for 354 diseases and injuries for 195 countries and territories, 1990-2017: a systematic analysis for the Global Burden of Disease Study 2017. Lancet 2018; 392: $1789-1858$
[2] Moon AM, Singal AG, Tapper EB. Contemporary epidemiology of chronic liver disease and cirrhosis. Clin Gastroenterol Hepatol 2019: doi:10.1016/j.cgh.2019.07.060

[3] Study GBoD. Accessed 3rd Jan 2020. https://vizhub.healthdata.org/ gbd-compare

[4] Byass P. The global burden of liver disease: a challenge for methods and for public health. BMC Med 2014; 12: 159

[5] Mokdad AA, Lopez AD, Shahraz S et al. Liver cirrhosis mortality in 187 countries between 1980 and 2010: a systematic analysis. BMC Med 2014; $12: 145$

[6] World Health Organization. Global hepatitis report. 2017: https:// www.who.int/hepatitis/publications/global-hepatitis-report2017/ en/ 
[7] de Franchis R, Baveno VIF. Expanding consensus in portal hypertension: Report of the Baveno VI Consensus Workshop: Stratifying risk and individualizing care for portal hypertension. J Hepatol 2015; 63: 743-752

[8] Hassan C, Aabakken L, Ebigbo A et al. Partnership with African Countries: European Society of Gastrointestinal Endoscopy (ESGE) - Position Statement. Endosc Int Open 2018; 6: E1247-E1255

[9] Karstensen JG, Ebigbo A, Aabakken L et al. Nonvariceal upper gastrointestinal hemorrhage: European Society of Gastrointestinal Endoscopy (ESGE) Cascade Guideline. Endosc Int Open 2018; 6: E1256E1263
[10] Ebigbo A, Karstensen JG, Aabakken L et al. Esophageal stenting for benign and malignant disease: European Society of Gastrointestinal Endoscopy (ESGE) Cascade Guideline. Endosc Int Open 2019; 7: E833-E836

[11] Milholland AV, Wheeler SG, Heieck JJ. Medical assessment by a Delphi group opinion technic. N Engl J Med 1973; 288: 1272-1275

[12] Shiha G, El-Sayed SS. Gastric variceal ligation: a new technique. Gastrointest Endosc 1999; 49: 437-441 